\title{
Ensinando Lógica de Programação aplicada à Robótica para alunos do Ensino Fundamental
}

\author{
Lia Alessandra da S. Martins ${ }^{1}$, Amanda da S. Brelaz ${ }^{1}$, Gabriel R. Nascimento ${ }^{1}$, \\ Raíssa M. Alfaia ${ }^{1}$, Thaís dos S. Martins ${ }^{1}$ \\ ${ }^{1}$ Instituto Federal de Educação, Ciência e Tecnologia do Amazonas (IFAM) - Campus \\ Parintins \\ Estrada Odovaldo Novo, s/n, Bairro: Aninga/Paranema - 69.152-470- Parintins - AM - \\ Brazil \\ \{liaalessandra, amandabrelaz22, gabrielramosnascimento195, \\ isaalfaaias2\}@gmail.com, thais-stsm@outlook.com
}

\begin{abstract}
This article presents the project developed in school Pe. Francisco Luppino - SESI, in Technological Education and Technological Projects discipline, where students of Integrated Computer Technician Course from IFAM - Campus Parintins which stand out in programming language help others students to 5th, 6th and 7th grade, in classes of these disciplines. Applying and demonstrating the concepts that were acquired during the technical course, referring to Logic Programming. Adhering to the robot programming Lego Mindstorms EV3 as focus, with the main objective to encourage students to join the field of Information Technology .
\end{abstract}

Keywords: LEGO MINDSTORM EV3, Programming, Technological Education.

Resumo. Este artigo apresenta o projeto executado na escola Pe. Francisco Luppino - SESI, nas disciplinas Educação Tecnológica e Projetos Tecnológicos, onde os alunos do Curso Técnico Integrado em Informática do IFAM - Campus Parintins, que se destacam na parte de programação, auxiliam os alunos de $5^{\circ}$, $6^{\circ}$ e $7^{\circ}$ ano, nas aulas destas disciplinas. Aplicando e demonstrando os conceitos que foram adquiridos no decorrer do curso técnico, referente a Lógica de Programação. Aderindo como foco a programação de robôs LEGO MINDSTORM EV3, tendo como objetivo principal incentivar os discentes a ingressarem na área de Tecnologia da Informação.

Palavras-chave: LEGO MINDSTORM EV3, Programação, Educação

Tecnológica.

\section{Introdução}

Os avanços tecnológicos crescem a cada dia, aprimorando consigo a rapidez no processamento de informações, na tecnologia do nosso cotidiano, como por exemplo: nas telecomunicações, nas indústrias, no comércio, em nossas próprias casas e nas escolas e criando novas ferramentas para facilitar nossa vida. Segundo Pereira [2010], os robôs são hoje instrumentos fantásticos criados pelo homem e usados a seu serviço. Estas máquinas são usadas nas mais diversas áreas e com as mais diversas finalidades, interagindo e adaptando-se ao meio. Com isso acreditamos que o computador e os novos avanços tecnológicos como os robôs, são ferramentas úteis para o ensino/aprendizagem. 
V Congresso Brasileiro de Informática na Educação (CBIE 2016)

Anais do XXVII Simpósio Brasileiro de Informática na Educação (SBIE 2016)

Imagine uma criança que constrói o seu próprio brinquedo. E melhor ainda, ela adora brincar com ele, porque é bonito e tecnológico. O bônus, é que ela aprende muito enquanto o constrói e programa. Esse é apenas um dos benefícios de ensinar robótica para crianças. Em diversos países do mundo o ensino da robótica já faz parte da matemática, física e desenvolvem várias outras habilidades, como pensamentos mais específicos, lógicos e práticos [HAPPYCODE 2015].

Pensando em uma proposta mais interativa, os alunos do $3^{\circ}$ ano do curso Técnico Integrado em Informática do Instituto Federal de Educação, Ciência e Tecnologia do Amazonas - IFAM campus Parintins, firmaram parceria com a Escola Pe. Francisco Luppino - SESI, que possui como componente curricular as disciplinas Educação Tecnológica e Projetos Tecnológicos, tendo como premissa trabalhar com crianças cursando o $5^{\circ}, 6^{\circ}$ e $7^{\circ}$ ano do Ensino Fundamental, aplicando e ensinando noções básicas de lógica, algoritmo e programação, por meio de aulas teóricas e práticas, utilizando jogos de raciocínio lógico do site Racha Cuca e a programação em blocos com a ferramenta Scratch, para posteriormente, as crianças aplicarem os conhecimentos adquiridos na programação dos robôs LEGO MINDSTORM® Education EV3.

Durante esse caminho, a diversão e aprendizagem estão sempre juntas, com a ferramenta Scratch e os robôs LEGO fica muito mais fácil assimilar os princípios fundamentais da lógica de programação. Além disso, há o desenvolvimento do raciocínio lógico, a ampliação dos conhecimentos tecnológicos e o aprendizado do trabalho em grupo.

O presente trabalho tem como objetivo geral aplicar os conceitos adquiridos na disciplina Lógica de Programação, auxiliando alunos do $5^{\circ}, 6^{\circ}$ e $7^{\circ}$ ano na programação de robôs. Demonstrando de forma lúdica o uso da lógica, ensinando aos alunos conceitos e noções básicas de lógica de programação, para que eles desenvolvam capacidade de abstração na resolução de problemas, introduzindo o sistema LEGO MINDSTORM ${ }^{\circledR}$ Education EV3 para aplicação dos conceitos de programação adquiridos no kit de robótica educacional LEGO MINDSTORM ${ }^{\circledR}$, com o intuito de despertar nos aprendizes o interesse pelos cursos da área de Tecnologia da Informação - T.I.

\section{Ensino da Lógica de Programação}

\subsection{Utilização da lógica para resolução de problemas}

Forbellone e Ebrspacher [2005] observam que, sendo o raciocínio a forma mais complexa do pensamento, a lógica estuda a "correção do raciocínio", colocando ordem no pensamento. Tendo em vista essas ideias, nota-se a importância da lógica na vida, não só como teoria, mas como prática, uma vez que, quando um ser humano quer pensar, falar, escrever ou agir corretamente, necessita colocar "ordem no pensamento", fazendo uso da lógica.

A capacidade de abstração é algo fundamental para o sucesso na aprendizagem de programação, principalmente para compreender problemas e propor soluções [ZANETTI e OLIVEIRA 2015]. Com base nisto, é necessário fomentar a capacidade de abstração e raciocínio lógico dos discentes para ter subsídios no ensino-aprendizagem de programação. Para isso, uma forma de desenvolver tal capacidade dá-se pela utilização de jogos digitais que estimulam o aluno se ater ao objetivo do jogo brincando. 
V Congresso Brasileiro de Informática na Educação (CBIE 2016)

Anais do XXVII Simpósio Brasileiro de Informática na Educação (SBIE 2016)

O site RachaCuca, segundo Serafim [2016], é um portal de entretenimento inteligente dedicado a todas as idades com jogos bastante atrativos e problemas de lógica, representado na figura 1 . A escolha da plataforma como ferramenta para auxiliar no desenvolvimento do raciocínio lógico é devido o sistema conter interface agradável ao usuário, contendo as instruções necessárias para a resolução dos problemas, a fim de que os alunos que utilizam tal plataforma concluam os jogos.

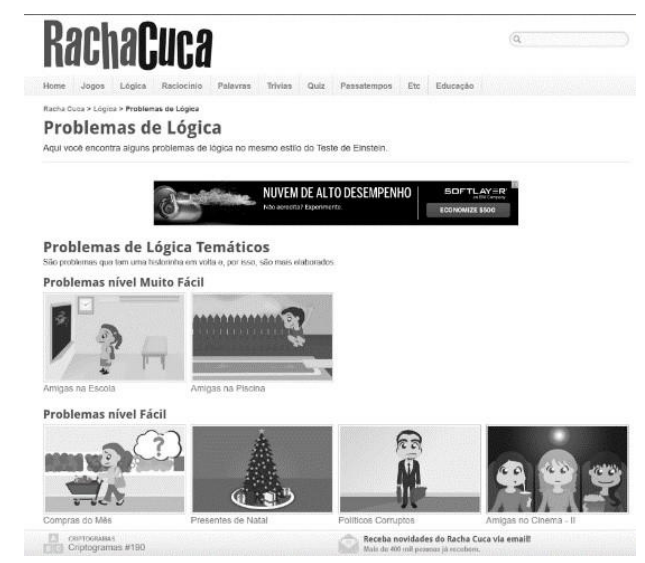

Figura 1. Plataforma RachaCuca - Módulo: Problemas de Lógica

\subsection{Uso da Ferramenta Scratch}

Conforme afirma Rodrigues [2015], o Scratch, apresentado na figura 2, é uma linguagem de programação disponível online, desenvolvida com o objetivo de possibilitar que iniciantes possam criar programas de computador sem aprender a sintaxe de uma linguagem de programação. A ideia é motivar o aprendizado de conceitos de programação por meio de uma experiência divertida, envolvendo os alunos na elaboração de projetos como animações interativas, jogos digitais [MALONEY 2010], entre outros recursos visuais.

De acordo com Zaharija [2013], com o apoio dos recursos do Scratch, a criança ou jovem aprende a pensar e a trabalhar de forma criativa, sistemática e colaborativa. A interface gráfica do Scratch, e o recurso de "blocos de comandos" organizados dentro de diversas categorias como "movimento", "loops" etc., permitem que os programas sejam desenvolvidos sem a necessidade de memorização de linguagens e códigos de programação. A programação é feita a partir de fragmentos de código, embutidos nos blocos de comandos de diferentes cores e formatos, que podem ser arrastados para uma janela onde o programa é construído.

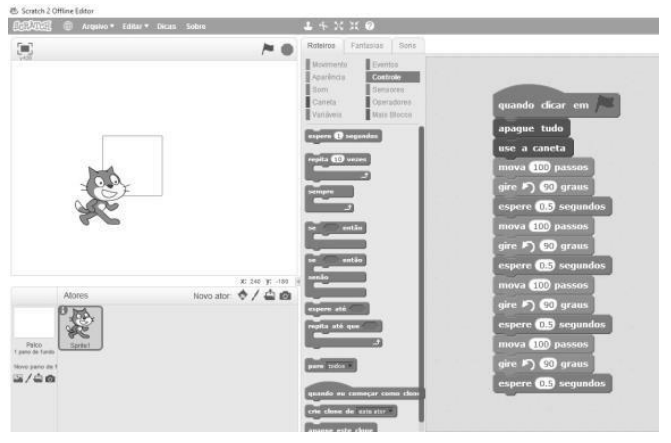

Figura 2. Ferramenta Scratch 
V Congresso Brasileiro de Informática na Educação (CBIE 2016)

Anais do XXVII Simpósio Brasileiro de Informática na Educação (SBIE 2016)

\subsection{Plataforma LEGO MINDSTORM®}

A plataforma LEGO MINDSTORM ${ }^{\circledR}$ é um kit educacional que consite em um conjunto tradicional de peças LEGO, um conjunto de sensores, atuadores e um "bloco inteligente" [BRITO e MADALOSSO 2014], o EV3 Brick, que funciona como a unidade de controle central. Segundo LEGO [2013], o EV3 Brick possui Sistema Operacional LINUX atuando com um microcontrolador ARM9 com $300 \mathrm{MHz}$, tendo $16 \mathrm{MB}$ de memória Flash e 64 MB de memória RAM (Random Access Memory). Este possui um monitor LCD monocromático com resolução de $178 \times 128$ pixels e quatro botões para navegar em sua interface com o usuário, usando menus hierárquicos, alimentação por 6 pilhas AA de 1.5 V (Volts) ou uma bateria de lítio, entre outras características.

Além disso, o EV3 Brick possui quatro entradas para sensores e quatro saídas para acionar os motores. Por padrão, ao adiquirir um kit LEGO MINDSTORM ${ }^{\circledR}$ Education EV3 que conforme LEGO [2016], "visa inspirar e desenvolver os construtores de amanhã através de brincadeiras criativas e aprendizagem", o usuário contará com um sensor ultrassônico para mensurar distâncias, dois sensores de toque, um sensor de cor, um sensor de rotação e três servos motores (com sensores incorporados), além de uma bateria de lítio. No entanto, o usuário ainda pode obter sensores adicionais, tais como sensores de cor, sensores ultrassônicos, entre outros. A figura 3 apresenta o EV3 Brick acoplado a seus sensores e servos motores.

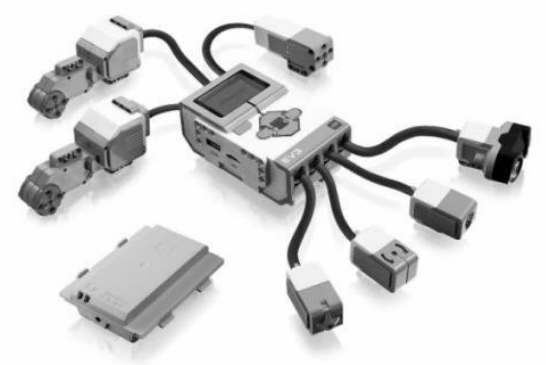

Figura 3. EV3 Brick

O conjunto de peças disponível permite montar robôs de diferentes formas, tais como veículos, animais e humanoides, entre outros. Estes podem ser programados com as funcionalidades desejadas, uma vez que o EV3 Brick possui uma porta USB 2.0 e também conta com comunicação Bluetooth e WiFi, através das quais pode-se enviar programas específicos desenvolvidos em computador. A plataforma LEGO MINDSTORM ${ }^{\circledR}$ já conta com uma IDE (Integrated Developme Enviroment) nativa para desenvolvimento de programas, o LEGO MINDSTORM ${ }^{\circledR}$ Education EV3. Esta é baseada no estilo drag and drop (do inglês, arrastar e soltar).

Por meio desta IDE é possível desenvolver programas de maneira simples, arrastando e conectando componentes mais básicos como loops (estruturas de repetição), waits (indicam que o robô deve esperar um determinado evento acontecer), comutação (estruturas de decisão) e até mesmo componentes mais avançados, tais como o Bluetooth. Existe um conjunto de botões que facilitam a compilação e execução do programa no EV3 Brick. 
V Congresso Brasileiro de Informática na Educação (CBIE 2016)

Anais do XXVII Simpósio Brasileiro de Informática na Educação (SBIE 2016)

\section{Materiais e Métodos}

A fim de promover de forma lúdica o ensino da robótica para os alunos do Ensino Fundamental, foram realizadas aulas teóricas e práticas no laboratório de informática, utilizando ferramentas para apresentar noções básicas de raciocínio lógico, conceitos e noções de programação, conforme o modelo abaixo:

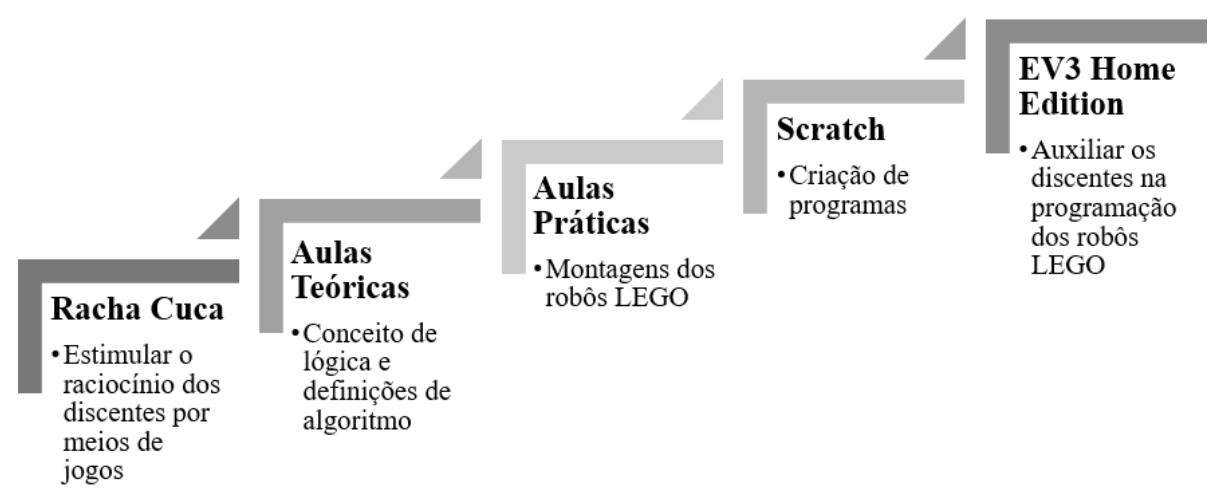

Figura 4. Modelo de métodos.

Inicialmente utilizou-se o site RachaCuca, onde foram selecionados jogos com níveis de dificuldade diferentes. Os jogos são: Pinguins numa fria; O Lobo, a Ovelha e o Couve; e Missionários e Canibais. No primeiro jogo há três pares de pinguins, os pais e seus respectivos filhos, cada um com uma cor diferente de cachecol; azul, vermelho e verde. O jogo pede para os alunos levarem os pinguins até a margem oposta, porém os pinguins pequenos ficam assustados longe de seus pais. Deixamos os alunos resolverem o problema e logo após solicitamos que nos explicassem a solução encontrada. No segundo jogo, os alunos tiveram como tarefa atravessar o lobo, o couve e a ovelha, mas tiveram que tomar cuidado, pois se o lobo e a ovelha ficassem sozinhos, o lobo devoraria a ovelha; se a ovelha ficasse sozinha com o couve, a ovelha comia o couve. Além disso, os alunos deviam ficar atentos, porque o barquinho do camponês comportava apenas um item, além dele próprio. Após concluírem os jogos, apresentamos o último jogo: Missionários e Canibais, onde os discentes tinham como tarefa atravessar os missionários para o outro lado da margem, porém, não era permitido deixar mais canibais do que missionários em qualquer uma das margens. Com os jogos foi possível concluir que os alunos possuem facilidade ao solucionar problemas por meio de estímulos do raciocínio lógico.

Continuando o processo, deu-se início as aulas teóricas, onde foram apresentadas em slides, definições de algoritmo, programa, lógica, lógica de programação, algoritmo na forma descritiva e posteriormente algoritmo na forma de fluxograma. Foram explanados alguns exemplos e solucionadas algumas atividades complementares no caderno dos discentes. Após serem trabalhados os principais conceitos nas aulas teóricas, partimos para as aulas práticas, como mostra a figura 5, onde os alunos fizeram a montagem dos robôs com os kits LEGO que, de acordo com Kerber [2010] "[...] emprega a abordagem construcionista". "O construcionismo possibilita ao aluno a construção subjetiva do conhecimento por meio de artefatos tecnológicos [...] possibilitam uma 
V Congresso Brasileiro de Informática na Educação (CBIE 2016)

Anais do XXVII Simpósio Brasileiro de Informática na Educação (SBIE 2016)

interação e aprendizagem maior pelo aluno frente à problematização apresentada" [RIBEIRO 2006].

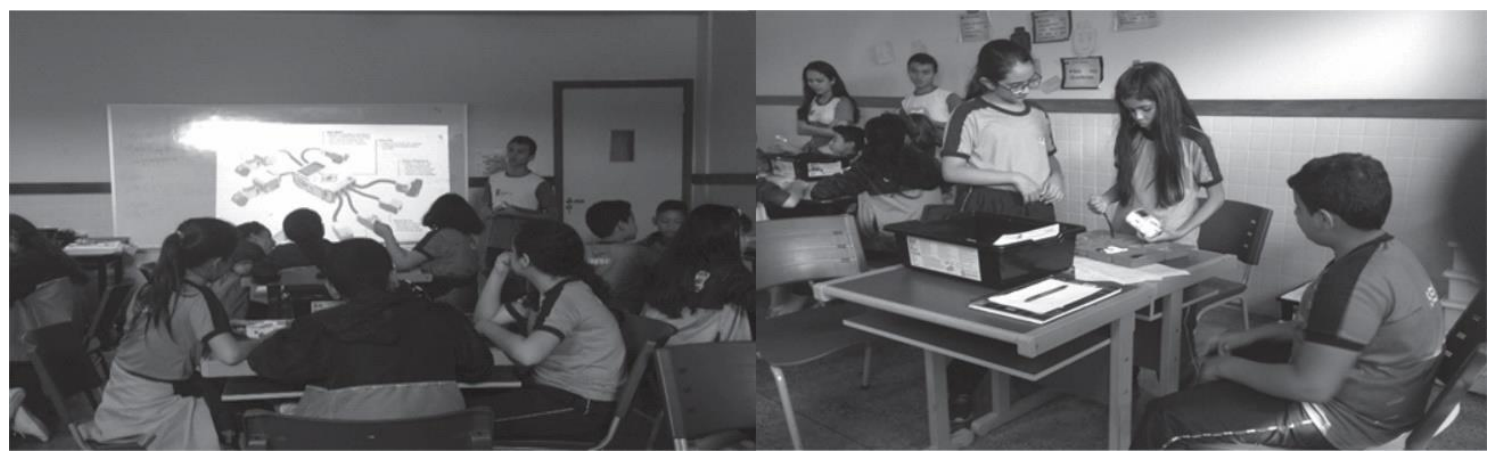

Figura 5. Alunos executando a montagem dos robôs do Kit LEGO MINDSTORM.

Posteriormente foi utilizado a ferramenta Scratch que "é uma ferramenta desenvolvida pelo Massachusetts Institute of Technology (MIT) com intuito de introduzir a programação de computadores para jovens sem conhecimento aprofundado da área" [...] uma linguagem de programação voltada principalmente para iniciantes que permite criar programas, histórias interativas, animações, jogos, música e arte" [SCRATCH 2016], onde foi feito a criação dos primeiros programas como apresentado na figura 6 .

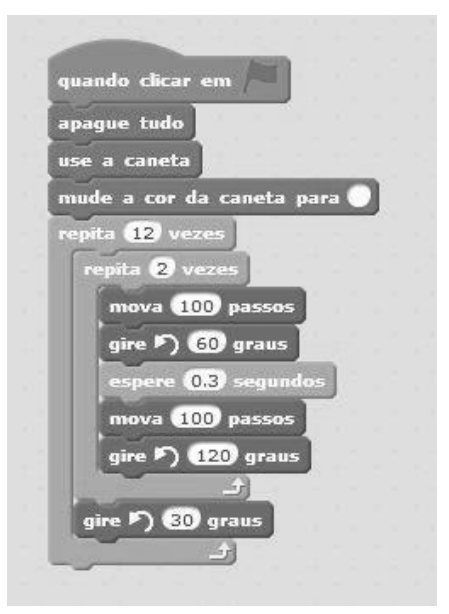

Figura 6. Programa feito no Scratch.

Logo após, partimos para o LEGO MINDSTORM® Education EV3: "Um software livre e fácil de ser manipulado, que apresenta missões e uma interface de programação simples" [LEGO 2016]. Além de obter uma forma lúdica de promover a iniciação a robótica, o software aborda também a teoria e a prática de conteúdos direcionados a robótica. Os alunos puderam assim, programar, inserir a implementação feita efetuando o download para a memória do robô e realizar os testes, o que podemos observar na figura 7. 
V Congresso Brasileiro de Informática na Educação (CBIE 2016)

Anais do XXVII Simpósio Brasileiro de Informática na Educação (SBIE 2016)

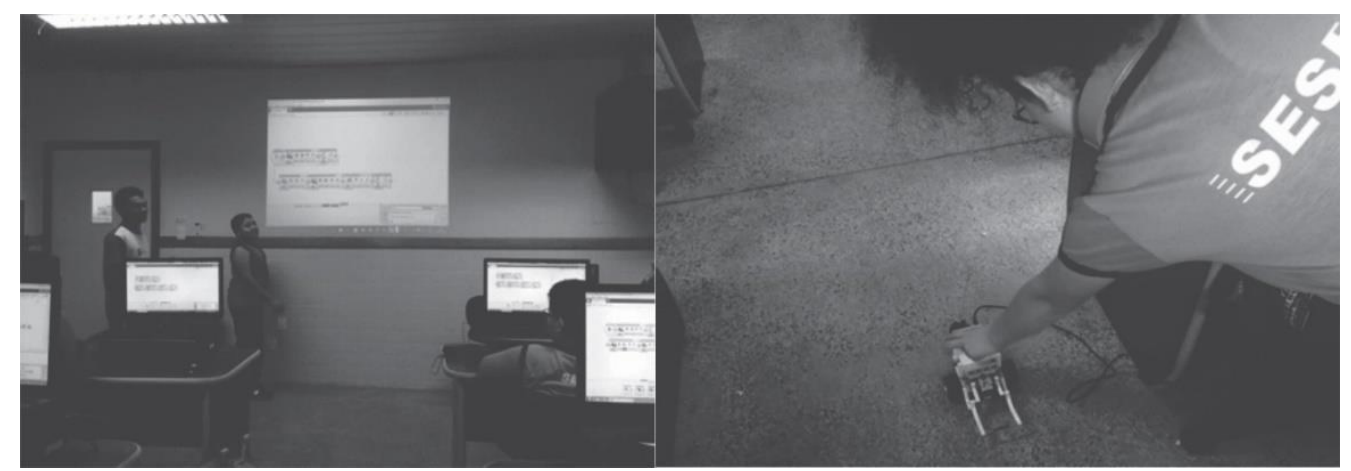

Figura 7. Alunos programando no software LEGO MINDSTORM Education EV3 e executando nos robôs LEGO.

\section{Resultados e Discussões}

Com a realização de aulas teóricas, foram explanados assuntos sobre programação e robótica por meio de atividades que estimularam a aprendizagem dos alunos através de recursos lúdicos como jogos online, montagem de robôs e programação em blocos em plataformas voltadas para a faixa etária de 10 aos 12 anos, contudo, as experiências em relação às turmas foram as mais diversas, em algumas turmas há mais facilidade para se ministrar as aulas, já em outras, se torna mais difícil para que dêem certo, com isso as formas metodológicas utilizadas se diferem de acordo com o comportamento dos discente, para assim obter bons resultados.

Para começar, a turma do $5^{\circ}$ ano matutino, possui nove alunos, três meninas e seis meninos, que são alunos participativos e curiosos para compreenderem os funcionamentos da robótica. Por serem os mais novos, são bastante empolgados e mais comportados, apenas com dois dos alunos há maior problema, pois os mesmos são agitados e tentam atrapalhar aulas, precisando de intervenção dos professores para que a aula prossiga normalmente. Em uma questão avaliativa, um dos discentes descreveu as aula de robótica da seguinte forma: "Elas estimulam a usar melhor a lógica do meu dia-a-dia na programação dos robôs, eu gosto muito." Abaixo se encontra o gráfico 1 com os resultados desta turma nas avaliações:

\section{$5^{\circ}$ Ano Matutino}

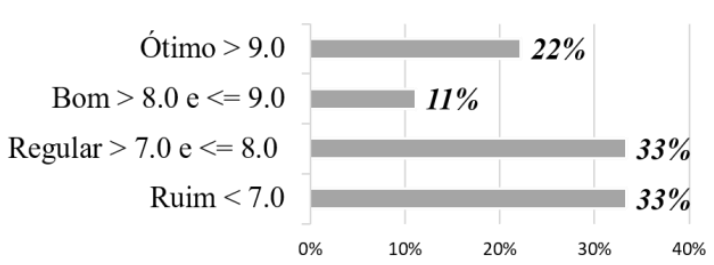

\section{$67 \%$ da Turma APROVADA}

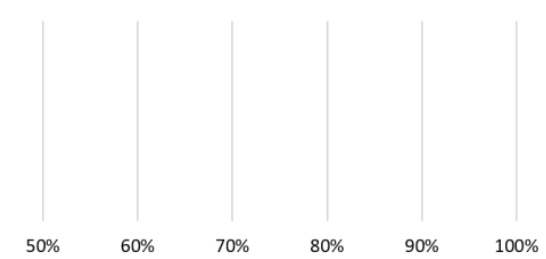

Gráfico 1. Rendimento da turma do 5 Ano Matutino

Os alunos do $5^{\circ}$ vespertino são parecidos com os do turno na manhã, porém com apenas nove alunos, onde apenas um aluno tenta desviar a concentração dos seus colegas por conta de sua agitação, entretanto ele interage e compreende os assuntos, assim como toda a turma que apesar da aula ser no último tempo, a mesma continua proveitosa. Para um aluno desta turma, "A aula é muito boa, interessante, onde aprendemos coisas como: 
V Congresso Brasileiro de Informática na Educação (CBIE 2016)

Anais do XXVII Simpósio Brasileiro de Informática na Educação (SBIE 2016)

lógica, robótica, algoritmos e coisas legais pra usar hoje e quem sabe no futuro". Para demonstrar o rendimento da turma, segue o gráfico 2 com resultado das avaliações:

$5^{0}$ Ano Vespertino

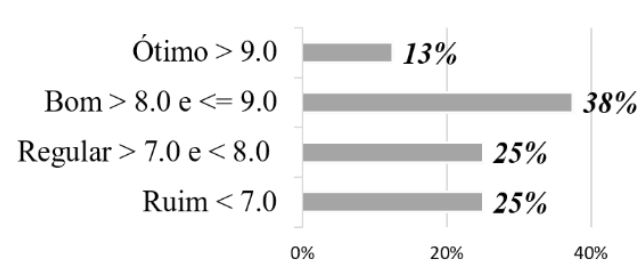

75\% da Turma APROVADA

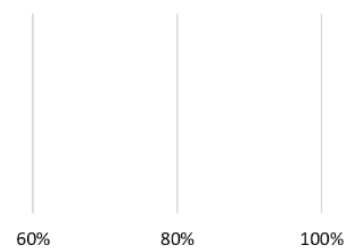

Gráfico 2. Avaliação 5o ano vespertino.

$\mathrm{Na}$ turma do $6^{\circ}$ ano matutino há vinte alunos, que em maioria estão as meninas e por elas há maior interesse, por conta disso, surgiram bons resultados em relação às atividades realizadas, percebemos também que apesar das metodologias lúdicas, alguns dos alunos no inicio, não mostravam interesse no ramo de T.I, nossa missão foi estimulálos a conhecer o ramo, o que atualmente, alguns já relataram em conversas informais que optam por seguir na área, assim como um dos aprendizes, que em seu relato disse: "Passe $i$ a me interessar mais no assunto de robótica e programação por conta da forma que os professores nos repassam, sendo mais interessante e sem dificuldades para eu entender". O gráfico 3 mostra a análise de rendimento das notas obtidas nas avaliações realizada pelos alunos.

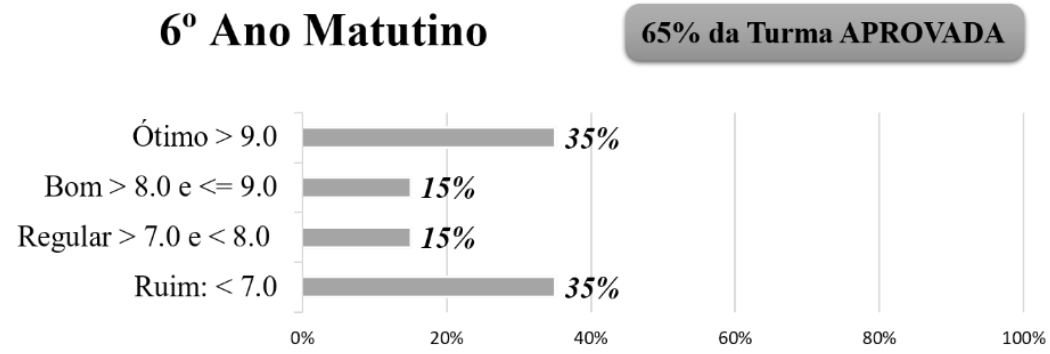

Gráfico 3. Avaliação 6ำ ano matutino.

O $6^{\circ}$ ano vespertino é uma turma grande e muito agitada, mas apesar das brincadeiras é bem esforçada. Os alunos se destacam por sua rapidez em desenvolver e resolver os problemas propostos em sala de aula. O rendimento da turma pode ser observado no gráfico 4. Um dos alunos relatou sua opinião sobre como é a situação de ministrar aulas nesta turma: "As aulas são legais e interativas, os professores ajudam bastante, só poderia melhorar o barulho na sala por causa dos bagunceiros”.

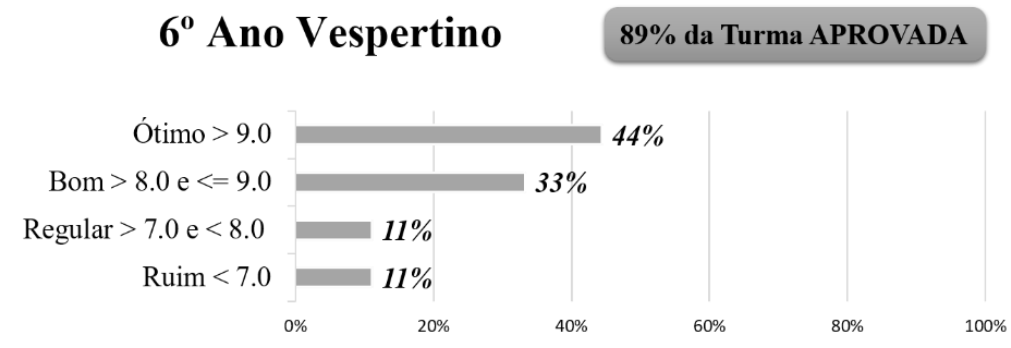

Gráfico 4. avaliação 6ำ ano vespertino. 
Os alunos da turma do $7^{\circ}$ ano matutino se destacam por serem os mais inquietos e também por serem os que têm mais experiência com robótica, pois muitos deles foram para a First League of LEGO onde trouxeram destaque ao estado do Amazonas. Os rendimentos dos estudantes pode ser acompanhado no gráfico 5. Segundo os discentes, as aulas são legais e contribuem para conseguirem as melhores notas e assim participarem do evento, que é uma das grandes motivações para os mesmos.

\section{$7^{0}$ Ano Matutino}

\section{5\% da Turma APROVADA}

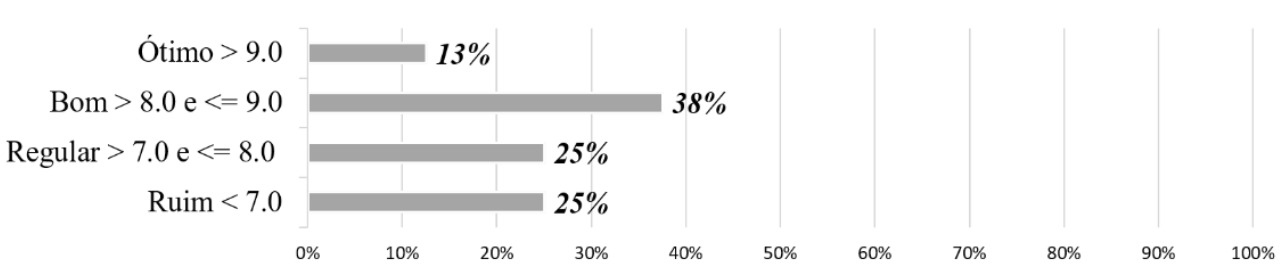

Gráfico 5. Avaliação $7^{\circ}$ ano matutino.

Por fim, não é uma tarefa simples ensinar programação a alunos de ensino fundamental, porém, como foram mostrados os gráficos acima, os resultados foram bastante positivos, pois há um bom índice de aproveitamento por parte das crianças e a missão de mostrar que é possível instruí-los desde cedo no ensino tecnológico foi concluída, entusiasmandoos a seguirem na área de T.I.

\section{Considerações Finais}

Neste projeto foi demonstrado que podemos utilizar a programação no ensino fundamental, utilizando jogos na plataforma online "Racha Cuca" (http://www.rachacuca.com.br), onde os alunos passaram por três jogos de dificuldades diferentes, desenvolvendo sua capacidade de abstração e raciocínio. Inicialmente os erros se repetiam não alterando o progresso dos jogadores, porém, ao serem estimulados a pensarem de uma nova forma, onde os mesmos criaram novas estratégias para assim, finalizarem os testes lógicos, também foram explicados aos aprendizes os conceitos sobre lógica de programação, na qual houve grande participação e interesse por parte dos mesmos.

Ao avançar o conteúdo para o aplicativo Scratch, percebeu-se nos discentes grande capacidade de abstração e resolução dos programas, pois os conceitos de programação repassados nas aulas teóricas foram aplicados na prática. A partir do uso dos recursos do

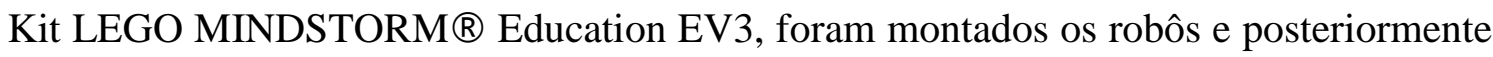
programados na própria plataforma $\mathrm{LEGO} \AA$, nesta fase do projeto houve maior empolgação dos envolvidos, pois foi visível a reação de felicidade das crianças a cada vez que o robô realizava uma tarefa proposta.

No decorrer do processo, observou-se maior dificuldade dos alunos para entender os conceitos. Já na parte prática, os discentes adoraram e apresentaram um ótimo rendimento, onde foi trabalhado com a ferramenta Scratch. Já quando foram aplicados os conceitos de programação no software do LEGO MIDSTORMS Education EV3, os estudantes mostraram-se relutantes em operar a ferramenta de forma correta, devido a IDE ser composta por itens bastante técnicos, o que dificultou muito a compreensão das crianças. O que foi revertido por meio de explicação individual e identificação dos tipos 
V Congresso Brasileiro de Informática na Educação (CBIE 2016)

Anais do XXVII Simpósio Brasileiro de Informática na Educação (SBIE 2016)

de blocos por cores, o que ajudou bastante o entendimento e a execução das tarefas propostas.

Por parte dos envolvidos, a sensação foi de dever cumprido, principalmente com o relato de um aprendiz, que por meio de sua avaliação diz que: "Passei a me interessar mais no assunto de robótica e programação por conta da forma que os professores nos repassam, sendo mais interessante e sem dificuldades para eu entender". Portanto, os objetivos foram alcançados com êxito, despertando nos alunos o interesse pela área de tecnologia da informação.

\section{Referências}

BRITO, R. C.; MADALOSSO, E.; GUIBES, G. A. O. (2014) "Seguidor de Linha Para LEGO ${ }^{\circledR}$ MINDSTORM Utilizando Controle PID”, In: Computer on the Beach 2014.

FERBELLONE, H. F.; EBERSPACHER, H. F. (2005). "Lógica de programação: a construção de algoritmos e estruturas de dados”, 3. Ed. Pearson Prentice Hall, São Paulo.

KERBER, F. M.; GUEDES, A. L.; GUEDES, F. L. (2010) "Experimentando A Tecnologia Lego Mindstorms", In: XL Congresso Brasileiro de Educação em Engenharia-COBENGE 2012.

LEGO (2013). Guia do Usuário. LEGOeducation.com/MINDSTORM. p. 69.

LEGO (2016). EV3 Software. Fonte:

http://www.lego.com/enus/MINDSTORM/downloads/download-software.

LEGO (2016). LEARN TO PROGRAM - IT' EASY. Fonte: http://www.lego.com/enus/mindstorms/learn-to-program.

MALONEY, J.; RUSK, N.; SILVERMAN, B.; EASTMOND, E. (2010) "The Scratch programming language and environment", In: ACM Transactions on Computing Education (TOCE), 10 (4), 16.

RIBEIRO, C. R. (2006) RobôCarochinha: "Um estudo Quantitativo sobre a Robótica Educativa no $1^{\text {o }}$ ciclo do Ensino Básico”. 189 f. Mestrado em Educação (Tecnologia

Educativa) - Universidade do Minho, Braga, 2006. Fonte:

http://repositorium.sdum.uminho.pt/bitstream/1822/6352/2/testeRoboticaCeliaribeiro

Final.pdf.

RODRIGUES, Carla Lopes; ZEM-LOPES, Aparecida M.; MARQUES, Leonardo; ISOTANI, Seiji. (2015). "Pensamento Computacional: transformando ideias em jogos digitais usando o Scratch". In: Anais do XXI Workshop de Informática na Escola (WIE 2015).

SCRATCH. (2016) ABOUT Scratch (Scratch Documentation

Site). Fonte: http://scratch.mit.edu/about/.

SERAFIM, Tiago. (2016) RachaCuca. Fonte: http://www.rachacuca.com.br/

ZAHARIJA, G.; MLADENOVIC, S.; BOLJAT, I. (2013) "Introducing basic Programming Concepts to Elementary School Children", Procedia - Social and Behavioral Sciences, vol. 106, pp. 1576-1584. 
V Congresso Brasileiro de Informática na Educação (CBIE 2016)

Anais do XXVII Simpósio Brasileiro de Informática na Educação (SBIE 2016)

ZANETTI, Humberto A. P.; OLIVEIRA, Cláudio L. V. (2015). Prática de ensino de Programação de Computadores com Robótica Pedagógica e aplicação de Pensamento Computacional. In Anais dos Workshops do IV Congresso Brasileiro de Informática na Educação (CBIE 2015) 